\title{
Race and Justice System Attitude Formation During the Transition to Adulthood
}

\author{
Adam Fine $^{1}$ (D) Elizabeth Cauffman ${ }^{1}$
}

Received: 20 July 2015 / Revised: 8 November 2015 / Accepted: 13 November 2015 /

Published online: 8 December 2015

(C) Springer International Publishing AG 2015

\begin{abstract}
Purpose Although attitudes towards the justice system are directly related to crime commission, few studies have examined how these attitudes develop from adolescence through early adulthood. Further, despite knowledge that minority youth experience disproportionate contact with the justice system, it is unknown how legal socialization differs by racial group. This study investigates how attitudes towards the justice system develop as youth transition into adulthood, examines how personal experiences with the justice system affect legal socialization, and determines whether developmental processes differ for Black, White, and Latino youth.

Methods Data were obtained from a 7-year longitudinal study of male offenders ( $N=$ 1114). Individual growth curve models were used to examine attitude formation from adolescence into adulthood. Time-varying effects models were used to examine how experiences with the justice system affect legal socialization.

Results Findings indicate that Black youth hold the most negative views of the system during adolescence, followed by Latino youth, and White youth. These racial differences become more pronounced as youth transition into adulthood. Further, although legitimacy and legal cynicism follow similar developmental trajectories, personal contacts with the justice system only affect legitimacy.

Conclusions Legal socialization from adolescence into young adulthood varies by race. The mechanisms that affect Black youth's attitudes do not affect Latino youths' attitudes, indicating that aggregating racial groups may mask meaningful differences. Despite engaging in the same amount of offending as White and Latino youth, Black youth are disproportionately contacted by the system. These disproportionate justice system contacts erode their perceptions of its legitimacy.
\end{abstract}

Adam Fine

finea@uci.edu

Elizabeth Cauffman

cauffman@uci.edu

1 Social and Behavioral Sciences Gateway 4222, University of California, Irvine, Irvine,

CA 92697, USA 
Keywords - Race and procedural justice $\cdot$ Legal socialization $\cdot$ Transition to adulthood

Attitudes towards the justice system are directly related to both crime commission and compliance with authorities $[1,10,24,43,60,61]$. Decades of research demonstrate that personal experiences with justice system actors directly contribute to one's attitudes towards the justice system $[7,8,11,39,58,60]$. However, although crime peaks during the late adolescent years, only a handful of such legal socialization studies have focused on adolescence $[1,6,26,31,35,39,46]$. In addition, even though minority youth are arrested at far greater rates than White youth and are consistently overrepresented in the justice system [40, 41, 52], even fewer legal socialization studies have examined whether legal socialization differs by racial groups [see 4, 37, 44, 66]. Considering that juveniles often come into repeated contact with justice system officials, juvenile offenders' attitudes towards the justice system may change considerably during adolescence and the transition to adulthood. Understanding whether such attitudes remain stable or undergo significant changes through this transition is highly important because attitudes that are developed during adolescence not only affect their immediate behavior, but likely influence their behavior into adulthood $[35,60]$.

\section{Race and Legal Socialization}

Legal socialization is how attitudes towards the justice system develop, involving both feelings of legitimacy and cynicism [7, 11, 39, 58]. Specifically, individuals who view the justice system and its authorities as more legitimate report greater confidence in the law and express a sense of obligation to defer voluntarily to its rules, decisions, and directives $[39,54,60]$. Importantly, in general, these individuals more easily accept the decisions of legal officials. The legal socialization process also involves the development legal cynicism. Legal cynicism is a frame through which individuals interpret the viability of the law and its agents [46, 51]. Legal cynicism thus refers to the degree to which individuals feel that the law does not apply to them or the degree to which an individual feels violating the law can be reasonable $[11,25,46]$. Legitimacy and legal cynicism have been the focal attitudes in legal socialization research because decades of empirical research suggest that those who perceive the justice system to be more legitimate or harbor less cynicism towards the law are more likely to cooperate with authorities, comply with directives, and engage in less delinquency see: [1, 10, 24, 60, 61].

As detailed by Fagan and Tyler [11], legal socialization is the product of accumulated interactions with legal authorities. In this framework, personal experiences with justice system actors play an especially important role in shaping a person's views about the system $[34,60]$. For example, the way a police officer interacts with a youth affects how the youth views the justice system. If the youth feels as though he was treated unfairly, he is likely to view the system more negatively. Importantly, compared with White youth, minority youth are more likely to come into contact with justice system officials and describe the procedures used by legal authorities as more unfair [3, 4, 17, 18, 27, 32]. Indeed, Black youth consistently report more negative attitudes towards the police than White youth $[23,33]$. These experiences likely lead minority youth to feel bias and injustice towards the justice system [50]. 
However, as there has been limited research about race/ethnicity and offending over the life course [see 36], few studies have taken race/ethnicity into consideration when studying how youth perceive the justice system. In fact, the majority of legal socialization studies tend to compare White versus "non-White" rather than analyze White, Black, and Latino youth separately [4, 18, 44], largely because of limited sample sizes [64]. Though racial minority groups have historically viewed the justice system as less legitimate than White youth, there is likely a "racial hierarchy" stratified by White, Latino, and Black youth [65]. Latinos tend to face more intense criminalization and policing than Whites, but less criminalization than Blacks see [18]. However, studies do not consistently find that Latino youth perceive the justice system more positively than Black youth [see a review by 33]. Considering Latinos constitute a large and rapidly increasing proportion of the US population, such research is clearly necessary [64].

In addition, the majority of these studies have been cross-sectional or have compared youth at different ages. Negative effects of unfair treatment by legal authorities on legal socialization are expected to become more pronounced as experiences accumulate over time [60], yet existing research using cross-sectional methodology has not been able to investigate this directly. As such, the goal of this study will be to address this issue by following youth longitudinally. Indeed, considering that minority youth are more likely to come into contact with justice system officials, even after accounting for differences in self-reported delinquency [see 52,60], it is likely that minority youth would report less legitimacy and more cynicism particularly at older ages once they have more experiences with justice system officials. As a result, though it is likely that the legal socialization process during adolescence differs by racial group, the results of crosssectional studies are mixed and it is unknown whether any differences become more pronounced as youth transition to adulthood.

The few studies that examine justice system attitudes through adolescence are worthy of review. Fagan and Tyler [11] examined legitimacy and legal cynicism ratings in community youth ages 10 to 16 . The results of their study indicated that older youth report both less legitimacy and more cynicism than younger youth. The researchers concluded that legitimacy likely decreases and cynicism likely increases through adolescence, yet such developmental conclusions were limited by their crosssectional design. More recently, Nivette et al. [32] conducted a longitudinal analysis of legal cynicism among a sample of community youth in Switzerland. These researchers found that cynicism was relatively stable between ages 13 and 15, and that self-reported delinquency was the strongest predictor of legal cynicism. The researchers concluded that ongoing social interactions and experiences during adolescence likely affect legal socialization. However, because they only followed their participants for 2 years until age 15, it is unknown whether the findings generalize to late adolescence and young adulthood. Further, similar to Fagan and Tyler [11], analyses were not conducted by race/ethnicity, nor did the researcher sample adolescent offenders. If legal socialization is the product of accumulated interactions with legal authorities [11, 60], and if the negative effects of unfair treatment by legal authorities on legal socialization become pronounced as experiences accumulate over time [60], the legal socialization of adolescent offenders would likely be different than the legal socialization of community youth.

Two studies have examined legal socialization among adolescent offenders. Both studies by Piquero and colleagues used the Pathways to Desistance dataset. Youth in 
this study were serious adolescent offenders, ages 14 to 18 at baseline. In the first study, Piquero et al. [39] examined the development of legitimacy and legal cynicism over the course of 18 months. Using group-based trajectory analyses, they modeled changes in legitimacy and cynicism over time using the assessment wave number as their time variable. Their analyses suggested that there were four group trajectories for cynicism and five group trajectories for legitimacy. For both attitudes, the groups were primarily differentiated by baseline differences, and such differences remained relatively stable over the 18-month period. At the same time, they found strong age effects, such that older youths were more likely to view the law as less legitimate. However, because the authors modeled time using assessment wave rather than participant age, they were unable to test whether the older youths in this study had always viewed the law as less legitimate, or if such attitudes worsened over time.

More recently, Piquero and colleagues [37] used the same dataset to examine the stability of legal socialization of first-generation immigrants, second-generation immigrants, and native US-born youth over the course of 3 years. Again, modeling time using assessment wave, these researchers found that legal socialization does change over a 3-year period. However, because the researchers analyzed their data by wave rather than by age, it is unknown whether attitudes are formed in early adolescence or if they continue to develop through the developmental period. Further, because they only tracked youth for 3 years, they were unable to measure whether legal socialization remains stable though late adolescence and into early adulthood.

Together, these studies set an important foundation for examining the legal socialization of adolescent offenders. The present study advances our understanding of legal socialization of justice system legitimacy and legal cynicism in several ways. To our knowledge, this is the first study to analyze two aspects of legal socialization among youth offenders as they transition through adolescence and into young adulthood. Few prior studies have examined legal socialization among adolescent offenders, and to our knowledge, none have followed youth through early adulthood. One would expect that legal socialization would change considerably during this time period, reflecting ongoing personal interactions with the justice system. Accordingly, we examine how personal experiences with the justice system affect developmental legal socialization. Considering the salience yet limited understanding of how race/ethnicity may affect the development of legal attitudes, we track the legal socialization of White, Black, and Latino youth offenders from adolescence through early adulthood.

\section{Method}

\section{Participants}

Participants were male adolescents enrolled in the Pathways to Desistance study, a prospective study of serious juvenile offenders in Phoenix $(n=527)$ and Philadelphia $(n=589)$ (see [47], for complete details of study methodology). Adolescents were eligible for study participation if they were between the ages of 14 and 17 and had been charged with a felony or similarly serious non-felony offense (e.g., misdemeanor weapons offense). Because a large proportion of offenses committed by adolescents are drug offenses, the proportion of males whose enrollment offense was a drug offense 
was capped at $15 \%$ of the sample at each of the sites. All youths whose cases were being considered for trial in the adult system and had been arraigned were eligible for enrollment. Of eligible youths, $67 \%$ of those whom we located and invited to participate in the research agreed to enroll in the study $(N=1354)$. Compared with youths who declined to participate, enrolled participants had more prior arrests leading to formal charges (2.1 vs. 1.5 for nonparticipants), were somewhat younger at first arrest (13.9 vs. 14.2 years for nonparticipants), and were somewhat more likely to be non-Latino White ( 25 vs. $20 \%$ for nonparticipants). Although statistically significant, these differences are modest in magnitude.

The baseline interview was conducted an average of 36.9 days $(\mathrm{SD}=20.6)$ after participants' adjudication in the juvenile system, or, if participants were eligible for prosecution as an adult, their decertification (i.e., waiver) hearing in Philadelphia, or their adult arraignment in Phoenix. At the time of the baseline interview, this group of participants was, on average, 16.5 years of age $(\mathrm{SD}=1.11)$ and predominantly of lower socioeconomic status. Less than $4.4 \%$ of the participants' parents held a 4-year college degree, and less than $40 \%$ of participants' parents had less than a high school education. The race/ethnic backgrounds of participants were as follows: $41 \%$ Black, $34 \%$ Latino American, $20 \%$ non-Latino White, and $5 \%$ Other. Because there were so few participants in the "Other" category, they were not included in these analyses. Males comprise $86.4 \%$ of the overall study sample. Analyzing males and females separately would be ideal, particularly considering the potential sex differences in legal socialization [37]. However, only data from males $(N=1164)$ were used for this study because time-varying effects modeling requires a large sample size.

\section{Procedures}

Interviews were conducted every 6 months for the first 3 years and then yearly for the additional 4 years (total of 7 years). To create uniform time measurement for purposes of the present analyses, we combined data from the 6- to 36-month semiannual followup interviews into yearlong intervals, by averaging variables from the 6- and 12-month, the 18- and 24-month, and the 30- and 36-month interviews respectively [30]. The present analyses therefore include a total of 7 time points, each 1 year apart. Individuals had to provide data at both time points to have valid data for any annual period; of the 1164 male participants originally enrolled in this study, this requirement resulted in the loss of 48 participants from the analytic sample. Because the design of the study is an accelerated cohort design, there were different numbers of participants at each age group from 14 to 26 years ( 14 years, $n=137 ; 15$ years, $n=323 ; 16$ years, $n=630$; 17 years, $n=937 ; 18$ years, $n=962 ; 19$ years, $n=937 ; 20$ years, $n=920 ; 21$ years, $n=$ $919 ; 22$ years, $n=809 ; 23$ years, $n=610 ; 24$ years, $n=336 ; 25$ years, $n=69 ; 26$ years, $n=$ 2 ). Because there were so few participants at age 26 , analyses were limited to ages 14 to 25 for a total sample size of 1114 participants.

\section{Measures}

Legitimacy The measure of legitimacy follows from the measure employed by Tom Tyler [56, 60]. Using a 5-point scale ranging from Strongly Disagree to Strongly Agree, 
respondents indicated their agreement with 11 statements about the legitimacy of the justice system and its actors (e.g., "I have a great deal of respect for the police," or "The basic rights of citizens are protected in the courts"). Higher values indicate higher levels of perceived legitimacy of the law [57, 59]. Psychometric analyses of the scale at baseline indicated that it was reliable (alpha=.80; $\mathrm{CFI}=.92, \mathrm{RMSEA}=.07)$. Means and standard deviations at each age are presented in Table 1.

Legal Cynicism Following Sampson and Bartusch [46], our measure of legal cynicism asked respondents to rate their agreement with five statements (e.g., "Laws are meant to be broken"). Items assess the extent to which laws or rules are not considered binding in the present lives of participants [46]. Higher values on this scale indicate more legal cynicism (range 1-4). Psychometric analyses of the scale at baseline indicated that it was reliable $($ alpha $=.60 ; \mathrm{CFI}=.99, \mathrm{RMSEA}=.03)$. Means and standard deviations at each age are presented in Table 1.

Personal Contact with Justice System Officials We used two separate measures of personal contact with the justice system. First, using a life calendar approach, participants were asked at each yearly assessment whether they had been picked up by the police and been accused of committing a crime. Previous research suggests that retrospective data gathered using life calendar methods is accurate [16] and that the data structure of the life calendar fits the structure of respondents' autobiographical memories well [2]. For example, Caspi and Amell [5] found that life events reported 3 years earlier matched retrospective life history calendar data with over $90 \%$ accuracy. As such, the life calendar data collection method can provide a more continuous and complete representation of life events than is possible with other interview or questionnaire measures. The percent of participants who had been picked up by the police at each age is presented in Table 2 . As a result

Table 1 Means and standard deviations of legal socialization variables at each age

\begin{tabular}{|c|c|c|c|c|c|c|c|c|}
\hline \multirow[t]{2}{*}{ Age } & \multicolumn{4}{|l|}{ Legitimacy } & \multicolumn{4}{|c|}{ Legal cynicism } \\
\hline & All & White & Black & Latino & All & White & Black & Latino \\
\hline 14 & $2.50(.59)$ & $2.65(.67)$ & $2.34(.58)$ & $2.64(.58)$ & $1.98(.63)$ & $2.04(.71)$ & $1.88(.60)$ & $2.06(.60)$ \\
\hline 15 & $2.38(.57)$ & $2.44(.61)$ & $2.30(.55)$ & $2.40(.55)$ & $2.05(.55)$ & $1.94(.58)$ & $2.02(.55)$ & $2.14(.54)$ \\
\hline 16 & $2.32(.54)$ & $2.41(.57)$ & $2.22(.52)$ & $2.37(.52)$ & $2.08(.58)$ & $1.99(.62)$ & $2.05(.57)$ & $2.17(.53)$ \\
\hline 17 & $2.31(.53)$ & $2.44(.50)$ & $2.19(.53)$ & $2.35(.53)$ & $2.09(.55)$ & $1.99(.54)$ & $2.09(.57)$ & $2.12(.54)$ \\
\hline 18 & $2.31(.54)$ & $2.43(.50)$ & $2.18(.55)$ & $2.36(.52)$ & $2.09(.55)$ & $1.95(.51)$ & $2.08(.56)$ & $2.17(.56)$ \\
\hline 19 & $2.31(.56)$ & $2.47(.56)$ & $2.18(.52)$ & $2.36(.56)$ & $2.06(.55)$ & $1.89(.50)$ & $2.07(.54)$ & $2.14(.58)$ \\
\hline 20 & $2.31(.59)$ & $2.54(.55)$ & $2.16(.56)$ & $2.33(.58)$ & $2.02(.59)$ & $1.86(.53)$ & $2.01(.56)$ & $2.12(.61)$ \\
\hline 21 & $2.33(.63)$ & $2.53(.61)$ & $2.20(.59)$ & $2.36(.65)$ & $2.01(.61)$ & $1.85(.52)$ & $2.03(.58)$ & $2.08(.67)$ \\
\hline 22 & $2.32(.63)$ & $2.51(.64)$ & $2.18(.56)$ & 2.39 (.66) & $1.97(.61)$ & $1.86(.59)$ & $1.96(.57)$ & $2.04(.62)$ \\
\hline 23 & $2.32(.63)$ & $2.51(.57)$ & $2.16(.56)$ & $2.39(.64)$ & $2.11(.53)$ & $1.99(.52)$ & $2.09(.57)$ & $2.19(.55)$ \\
\hline 24 & $2.28(.61)$ & $2.50(.61)$ & $2.21(.57)$ & $2.24(.62)$ & $2.10(.52)$ & $1.99(.43)$ & $2.04(.47)$ & $2.23(.55)$ \\
\hline 25 & $2.24(.62)$ & $2.37(.64)$ & $2.12(.56)$ & $2.51(.67)$ & $2.10(.57)$ & $1.98(.54)$ & $2.01(.45)$ & $2.28(.58)$ \\
\hline
\end{tabular}


Table 2 Percent who reoffended, were picked up by the Police, or were rearrested by age

\begin{tabular}{|c|c|c|c|c|c|c|c|c|c|c|c|c|}
\hline \multirow[t]{2}{*}{ Age } & \multicolumn{4}{|c|}{ Self-report Reoffending } & \multicolumn{4}{|c|}{ Picked up by police } & \multicolumn{4}{|c|}{ Rearrested } \\
\hline & All & White & Black & Latino & All & White & Black & Latino & All & White & Black & Latino \\
\hline 14 & 0.99 & 1.00 & 1.00 & 0.98 & 1.00 & 1.00 & 1.00 & 1.00 & 0.09 & 0.04 & 0.07 & 0.13 \\
\hline 15 & 0.89 & 0.92 & 0.88 & 0.90 & 0.72 & 0.76 & 0.67 & 0.75 & 0.11 & 0.11 & 0.10 & 0.13 \\
\hline 16 & 0.87 & 0.86 & 0.86 & 0.88 & 0.60 & 0.60 & 0.61 & 0.60 & 0.17 & 0.13 & 0.17 & 0.20 \\
\hline 17 & 0.79 & 0.82 & 0.77 & 0.80 & 0.43 & 0.43 & 0.50 & 0.49 & 0.21 & 0.24 & 0.20 & 0.21 \\
\hline 18 & 0.65 & 0.70 & 0.64 & 0.64 & 0.28 & 0.22 & 0.32 & $0 . .25$ & 0.27 & 0.25 & 0.27 & 0.29 \\
\hline 19 & 0.57 & 0.63 & 0.57 & 0.54 & 0.22 & 0.25 & 0.24 & 0.18 & 0.35 & 0.32 & 0.37 & 0.34 \\
\hline 20 & 0.51 & 0.53 & 0.50 & 0.52 & 0.26 & 0.26 & 0.30 & 0.20 & 0.33 & 0.29 & 0.38 & 0.30 \\
\hline 21 & 0.48 & 0.59 & 0.43 & 0.46 & 0.27 & 0.27 & 0.30 & 0.25 & 0.32 & 0.28 & 0.33 & 0.33 \\
\hline 22 & 0.44 & 0.54 & 0.41 & 0.42 & 0.27 & 0.22 & 0.33 & 0.24 & 0.32 & 0.28 & 0.36 & 0.30 \\
\hline 23 & 0.43 & 0.53 & 0.38 & 0.43 & 0.26 & 0.25 & 0.30 & 0.23 & 0.35 & 0.30 & 0.40 & 0.31 \\
\hline 24 & 0.41 & 0.38 & 0.42 & 0.41 & 0.24 & 0.23 & 0.28 & 0.21 & 0.26 & 0.33 & 0.42 & 0.31 \\
\hline 25 & 0.35 & 0.44 & 0.34 & 0.35 & 0.20 & 0.22 & 0.19 & 0.20 & 0.35 & 0.33 & 0.42 & 0.20 \\
\hline
\end{tabular}

of small participant counts or low variability at certain ages, analyses were limited to ages 16 through 24 .

Second, official court records were used to assess whether youth had been rearrested during each follow-up period. The percent of participants who had been rearrested at each age is presented in Table 2. As a result of the small participant counts at certain ages and the large sample sizes necessary for analyzing intensive longitudinal data, analyses were limited to ages 14 through 24 . This construct enables us to examine the effects of two different types of justice system contact. The Pearson correlations between the types of contacts at each age were between .369 and $.553, p$ s $<.001$.

Self-reported Offending Involvement in antisocial activities was measured with the Self-report of offending [21]. Participants reported if they had been involved in any of 22 illegal behaviors (e.g., "Taken something from another person by force, using a weapon") during each follow-up period. Because the variable was highly positively skewed, responses were dichotomized into either did not reoffend or did reoffend. The percentage of participants who reoffended at each age is presented in Table 2.

Street Time Because incarceration can limit opportunity to engage in antisocial acts, failure to account for this can affect the identification of trajectories of antisocial behavior [38]. Youths reported on a calendar the number of days during the recall period that they had been in a detox/drug treatment program, psychiatric hospital, residential treatment program, or secure institution. All analyses controlled for street time, operationalized as the proportion of time in a year an individual was in the community. The amounts of exposure time reported for each 6-month period were averaged to derive the exposure time covariate for each annual interval [30]. 


\section{Plan of Analyses}

To examine whether the likelihood of reoffending, of being picked up by the police, or of being rearrested varies by race/ethnicity, we estimated random effects logit models. Each model controlled for amount of time on the streets, and the second and third models also controlled for self-reported offending. In the second set of models, we estimated individual growth curve models using linear mixed models containing both fixed and random effects [42, 49]. Models were estimated in three stages. First, we conducted unconditional means models for legitimacy and cynicism to examine whether there was sufficient between-persons variability to conduct multi-level modeling. Second, after establishing that there was sufficient between-persons variability, we conducted growth models to examine the average rate of change of each legal socialization measure over time. Third, we estimated conditional growth models to examine whether race/ethnicity accounts for the variability in legitimacy and legal cynicism. In all models, we treat time (i.e., age) as both a random and fixed effect to explain specific time effects as well as change over time. Mixed models conceptualize growth curve models using two levels of analysis [14, 42, 49]. The equations for the present analyses are as follows:

$$
\text { Level } 1: \text { LegalSocialization }_{\mathrm{ij}}=\pi_{0 \mathrm{i}}+\pi_{1 \mathrm{i}}\left(\mathrm{age}_{\mathrm{ij}}\right)+\mathrm{r}_{\mathrm{ij}}
$$

$$
\begin{array}{ll}
\text { Level 2: } & \pi_{0 \mathrm{i}}=\beta_{00}+\beta_{01}\left(\text { Race }_{\mathrm{ij}}\right)+\mathrm{u}_{0 \mathrm{i}} \\
& \pi_{1 \mathrm{i}}=\beta_{10}+\beta_{11}\left(\text { Race }_{\mathrm{ij}}\right)+\mathrm{u}_{1 \mathrm{i}}
\end{array}
$$

Combined equation:

$$
\text { LegalSocialization }_{\mathrm{ij}}=\beta_{00}+\beta_{01}\left(\operatorname{Race}_{\mathrm{ij}}\right)+\mathrm{u}_{0 \mathrm{i}}+\beta_{10}\left(\operatorname{age}_{\mathrm{ij}}\right)+\beta_{11}\left(\operatorname{age}_{\mathrm{ij}} * \operatorname{Race}_{\mathrm{ij}}\right)+\mathrm{u}_{1 \mathrm{i}}\left(\operatorname{age}_{\mathrm{ij}}\right)+\mathrm{r}_{\mathrm{ij}}
$$

The level 1 equation estimates within-person or intra-individual change over time, assessing individual growth rates. Here, time is treated as a random effect since we are generalizing individual effects across intervals of time. The level 2 model estimates interindividual change in predictors that are estimated as fixed effects. Race/ethnicity is included as a level 2 variable. Accordingly, the model assesses within-person variability in the level 1 predictors, or growth rates, as a function of level 2 predictors [14]. To capture and estimate the effects of specific time-varying factors on the slope (or rate of change) in the dependent variable, we include an interaction of time with each predictor at each time [14, 49]. Considering self-reported offending has been related to both legal cynicism and legitimacy [11, 32], we also included self-reported offending as a dichotomous level 1 covariate in these analyses. Since the proportion of the time spent on the streets also affects the ability to commit a variety of crimes, this variable is also used as a level 1 covariate [30, 38]. 
In the final set of models, we examine whether subsequent personal contact with the justice system (being picked up by the police and accused of a crime or being rearrested) affects legal socialization, using the same set of controls variables. Although multilevel or hierarchical models have been widely used to examine longitudinal data, they rely on a priori specifications of the functional form of how the independent variable affects change in the outcome. An extension of such methods, the time-varying effects model (TVEM), enables one to examine whether there is a timevarying relationship between the covariates and the outcomes [19, 28, 53, 55]. For example, if we were to model the effects of system contact on the development of attitudes towards the justice system using multilevel modeling, the equations for the conditional growth models (where 'SystemContact' refers to each independent predictor, modeled separately) would be:

Level 1: LegalSocialization $_{i j}=\pi_{0 i}+\pi_{1 i}\left(\operatorname{age}_{i j}\right)+\pi_{2 i}\left(\right.$ SystemContact $\left._{i j}\right)+\mathrm{r}_{i j}$

$$
\begin{aligned}
\text { Level 2: } & \pi_{0 i}=\beta_{00}+\beta_{01}\left(\operatorname{Race}_{i j}\right)+\mathrm{u}_{0 i} \\
\pi_{1 i} & =\beta_{10}+\beta_{11}\left(\operatorname{Race}_{i j}\right)+\mathrm{u}_{1 i} \\
\pi_{2 i} & =\beta_{20}+\beta_{21}\left(\operatorname{Race}_{i j}\right)+\mathrm{u}_{2 i}
\end{aligned}
$$

Combined equation:

LegalSocialization $_{i j}=\beta_{00}+\beta_{01}\left(\right.$ Race $\left._{i j}\right)+\beta_{10}\left(\operatorname{age}_{i j}\right)+\beta_{11}\left(\right.$ age $_{i j}{ }^{*}$ Race $\left._{i j}\right)+$
$\beta_{20}\left(\right.$ SystemContact $\left._{i j}\right)+\beta_{21}\left(\right.$ Race $_{i j}$ SystemContact $\left._{i j}\right)+\mathrm{u}_{0 i}+\mathrm{u}_{1 i}\left(\operatorname{age}_{i j}\right)+\mathrm{u}_{2 i}\left(\right.$ SystemContact $\left._{i j}\right)+\mathrm{r}_{i j}$

The equation thus pre-specifies a particular polynomial or other parametric form to the coefficient functions. It is rare, however, to observe behavior dynamics that follow a simple developmental pattern [63] because most individual trajectories are nonparametric. In contrast, in TVEM, these patterns take the form revealed directly from the data. Thus, TVEM reveals the shape of the coefficient functions over time without posing any parametric assumptions on these functions [53]. TVEM thus flexibly estimates how the association between a predictor and an outcome (e.g., legitimacy and cynicism) differs over continuous time (e.g., from age 14 to 25), without assuming the association follows a parametric function of time. Both the intercept and slope are time-specific and change their values at different points in time. That is, the coefficient for the time-varying predictor depends on time. For example, a simple TVEM equation is:

$$
\text { LegalSocialization }_{i j}=\beta_{0}(t)+\beta_{1}(t)\left(\text { SystemContact }_{i j}\right)+\epsilon_{i j}
$$

In this model, LegalSocialiation ${ }_{i j}$ refers to the normally distributed legal socialization variable (e.g., legitimacy), $\beta_{0}$ is the intercept parameter, $\beta_{1}$ is the slope parameter, SystemContact $_{i j}$ is the particular justice system experience variable (e.g., rearrest), and $\epsilon_{i j}$ refers to the normally distributed random errors. Importantly, the relations described 
by the intercept $\left(\beta_{0}(t)\right)$ and slope $\left(\beta_{0}(t)\right)$ are functions that summarize relations with values changing across time. Accordingly, the slope and intercept are modeled separately and are allowed to vary over time.

We fit a series of TVEM models using the recently developed SAS macro for normally distributed outcome variables [28, 67]. The complex function is split into several equally spaced intervals (knots), and each portion of a function is estimated. With this method, any complex function can be successfully approximated if a sufficient number of knots is specified. In the process of model selection, models with a different number of knots are compared using AIC and BIC values [48]. Following the recommendations of Shiyko and colleagues, we started with five knots and increased until AIC and BIC values were decreased. First, we estimated how each justice system contact variable was related to legitimacy. Models were run separately by each predictor and by each race/ethnicity to allow for time-varying race/ethnicity differences. Because all predictors were assessed at all waves, we estimated timevarying coefficients of time-varying predictors. We also controlled for self-reported offending and time on the streets at each age. These models were then repeated to predict legal cynicism. Results are presented as figures because time-varying coefficients are estimated in continuous time leading to a number of coefficients too large to present in tables [62].

\section{Results}

To examine whether reoffending rates or justice system contacts varied by race/ethnicity, we conducted a series of random effects logit models. All models controlled for time on the streets. White youth were used as the reference group, and analyses were repeated using Latino youth as the reference group. Results indicate that the likelihood of reoffending decreased for all youth as they transitioned from adolescence (age 14) into adulthood (age 25) (White $d y d x=-.393, p<.001$; Black $d y d x=$ $-.422, p<.001$; Latino $d y d x=-.429, p<.001)$. There were no differences in the likelihood of reoffending by race/ethnicity at any age (all $p$ 's $>.10$ ). Considering there were no differences in the likelihood of reoffending, we then examined whether the probability of being picked up by police varied by race/ethnicity. A series of random effects logit models were conducted, controlling for self-reported offending and proportion of time on the streets (Fig. 1). Results indicate that the likelihood of being picked up by the police decreased over time for all youth (White $d y d x=-.165, p<.001$; Black $d y d x=$ $-.073, p<.001$; Latino $d y d x=-.158, p<.001)$. However, there were racial differences in the probability of being picked up. Specifically, White and Latino youth were equally likely to be picked up over time $(p=.827)$. Black youth were more likely to be picked up by the police over time than White youth $(\mathrm{OR}=1.10, \mathrm{CI}=[1.03,1.16], p=.002)$ and Latino youth $(\mathrm{OR}=1.09, \mathrm{CI}=[1.04,1.15], p=.001)$. Considering the racial differences in the probability of being picked up by the police, we then conducted random effects logit models to examine whether the probability of being rearrested varied by race/ethnicity. Results indicate that the probability of rearrest increased over time for all youth (White $d y d x=.192, p<.01$; Black $d y d x=.279, p<.001$; Latino $d y d x=.174$, $p<.001)$ (Fig. 2). White and Latino are equally likely to be arrested over time $(p=.592)$. Black youth are significantly more likely to be rearrested over time than either White 


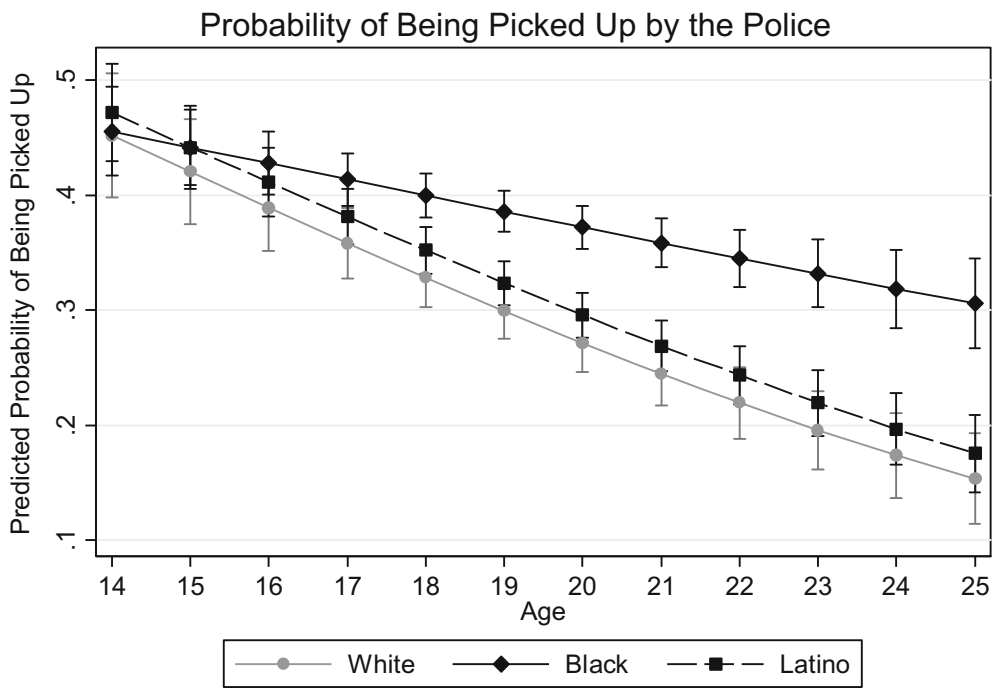

Fig. 1 Predicted probability of being picked up by the police by race

youth $(\mathrm{OR}=1.09, \mathrm{CI}=[1.02,1.17], p=.008)$ or Latino youth $(\mathrm{OR}=1.11, \mathrm{CI}=[1.05$, 1.17], $p=.001)$.

\section{Perceived Legitimacy of the Justice System}

In the second set of models, we estimated individual growth curve models using linear mixed models to examine whether subsequent personal contact with the justice system (i.e., being picked up by the police and accused of a crime or being rearrested) affect developmental changes in legitimacy. First, we conducted an unconditional means

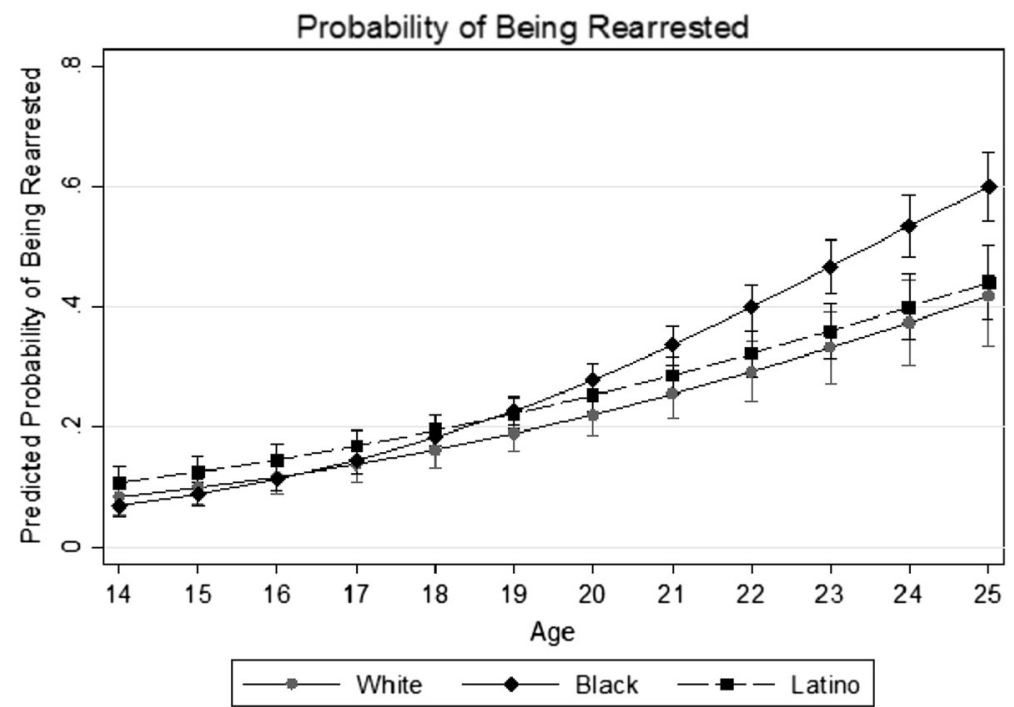

Fig. 2 Predicted probability of being rearrested by race 
model to understand developmental changes in legitimacy. The results of the unconditional means models suggest that $53.8 \%$ of the variability in legitimacy occurred between participants. The results of the unconditional growth model suggest that there was variability in the intercept and slope of legitimacy (Table 3). Results of likelihood ratio $\chi^{2}$ tests for legitimacy suggest that the random intercept is significant $\left(\chi^{2}=912.91\right.$, $p<.001)$ and random slope is significant $\left(\chi^{2}=3861.27, p<.001\right)$. Results of these unconditional means and unconditional growth models indicate that multi-level modeling is appropriate.

Once it was established that multi-level modeling was appropriate, we added race/ethnicity to the model to examine whether race/ethnicity accounts for significant variability in legitimacy (Fig. 3). It is important to note that these growth models appear different than the base means by age depicted in Table 1 because of the inclusion of the control variables. The likelihood ratio chi-square test between the model with and the model without race/ethnicity suggests that including race/ethnicity reduces error variability in legitimacy $\left(\chi^{2}=74.75, p<.001\right)$. Results of this model indicate that Black youth at age 14 reported lower legitimacy $(M=2.17)$ than White youth $(M=2.37$, $p<.001)$ and Latino youth $(M=2.34, p<.001)$ and continued reporting lower legitimacy than either group through age $25(p<.001)$. Latino youth did not report lower legitimacy than White youth at age $14(p=.587)$, but did start reporting lower legitimacy by age $17(p=.041)$ and continued reporting lower legitimacy through age $25(p<.001)$.

We then examine whether race/ethnicity accounts for the variability in legitimacy over time. Results of the likelihood ratio chi-square test suggest that including the interaction between race/ethnicity and age improves model fit for legitimacy $\left(\chi^{2}=7.05\right.$, $p=.029$ ) (Fig. 3). Results of a simple slopes analysis for legitimacy suggest that only the slope for White $(.016)$ is different from zero $(\mathrm{dy} / \mathrm{dx}=.016, p=.008)$ and is different from Black $(\mathrm{dy} / \mathrm{dx}=-.002, p=.010)$ and Latino $(\mathrm{dy} / \mathrm{dx}=-.001, p=.028)$. The slopes between Black and Latino are not significantly different from each other $(p=.730)$. Specifically, these findings indicate that the development of legitimacy varies by

Table 3 Unconditional growth models of legitimacy and legal cynicism

\begin{tabular}{|c|c|c|c|c|}
\hline & \multicolumn{2}{|c|}{ Legitimacy } & \multicolumn{2}{|c|}{ Legal cynicism } \\
\hline & $B$ & $S E$ & $B$ & $S E$ \\
\hline \multicolumn{5}{|l|}{ Fixed effects } \\
\hline Intercept & $2.27 * * *$ & .02 & $2.10 * * *$ & .02 \\
\hline Linear slope & $.01 *$ & $<.01$ & $-.01 * * *$ & $<.01$ \\
\hline \multicolumn{5}{|l|}{ Random effects } \\
\hline Intercept & $.22 * *$ & .01 & $.17 * *$ & .10 \\
\hline Linear slope & $.01 * *$ & $<.01$ & $.01 * *$ & $<.001$ \\
\hline Level 1 error & $.13 * *$ & $<.01$ & $.15^{* *}$ & $<.01$ \\
\hline \multicolumn{5}{|l|}{ Model fit } \\
\hline-2 log likelihood & 9472.80 & 9460.17 & & \\
\hline
\end{tabular}

$* p<.05, * * p<.01, * * * p<.001$ 


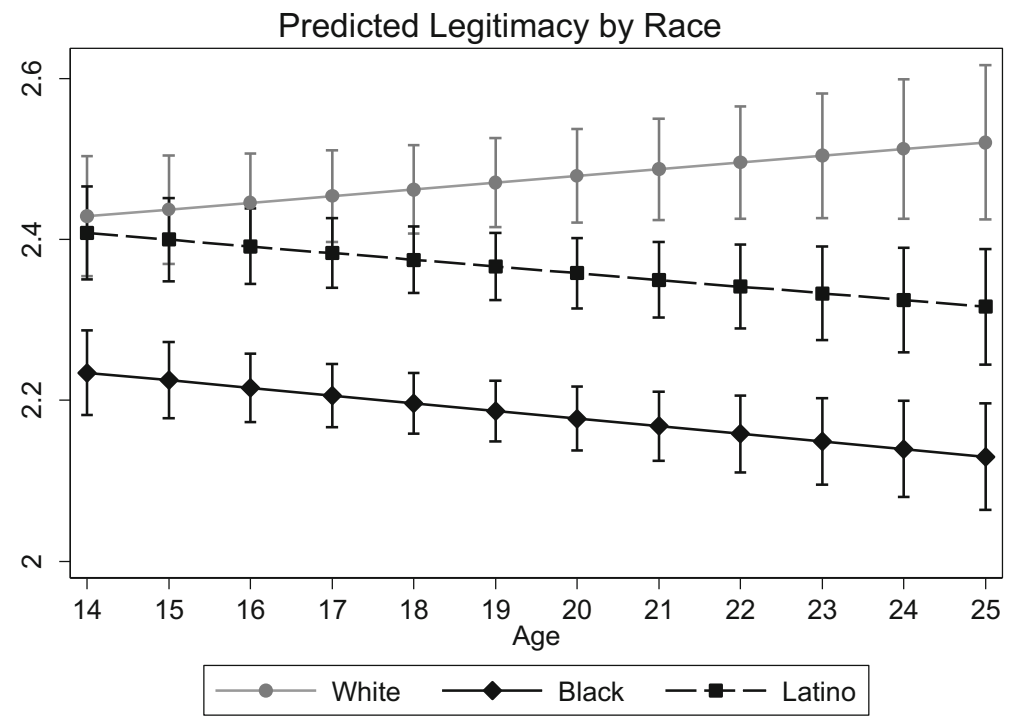

Fig. 3 Conditional growth model of legitimacy using race

race/ethnicity and that White youth, in particular, perceive the justice system as more legitimate over time.

Once it was established that the development of legitimacy varies by race/ethnicity, we used time-varying effects modeling to examine the effects of personal contacts with the justice system on legal socialization. Figures 4, 5, and 6 present the results of the analyses examining the time-varying effects of being picked up by the police on legitimacy, separately by race/ethnicity. Confidence intervals not containing zero indicate a significant effect of the predictor on the legitimacy rating at each age. For Latino

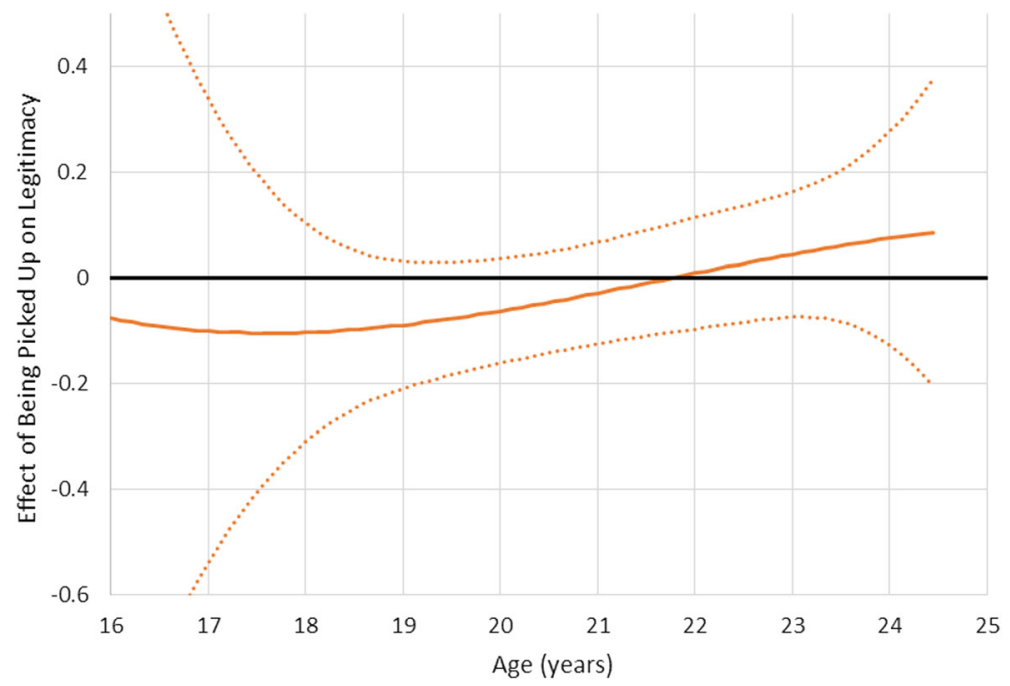

Fig. 4 Time-varying effects model of the effect of being picked up by the police on legitimacy scores for Latino youth. Note: Dotted lines indicate $95 \%$ confidence intervals. The $x$-axis indicates the effect of being picked up by the Police on youths' legitimacy ratings 


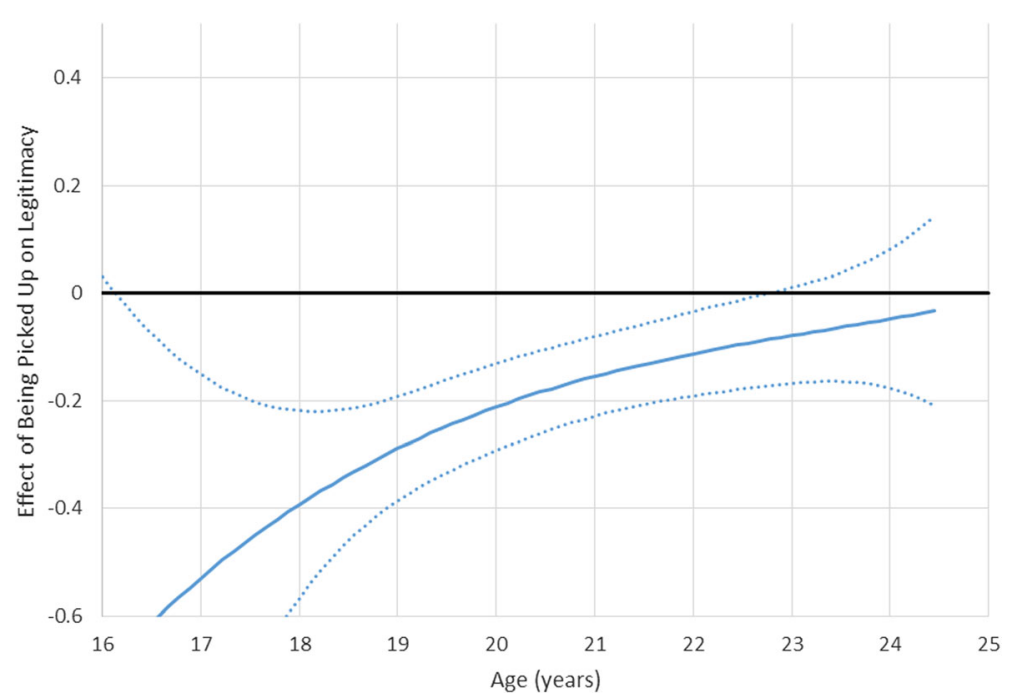

Fig. 5 Time-varying effects model of the effect of being picked up by the police on legitimacy scores for Black youth. Note: Dotted lines indicate $95 \%$ confidence intervals. The $x$-axis indicates the effect of being picked up by the Police on youths' legitimacy ratings

youth, being picked up by the police does not affect legitimacy ratings at any age. For Black youth, being picked up by the police reduces legitimacy from ages 16 to 23 . Similarly, for White youth, being picked up by the police affects legitimacy from ages 18 to 22 . Figures 7, 8, and 9 present the results of the analyses examining the timevarying effects of being rearrested on legitimacy ratings, separately by race/ethnicity. Results suggest that being rearrested does not affect legitimacy ratings of Latino youth at any age. However, being rearrested decreases legitimacy for Black youth from ages 18.5 through 24. Similarly, for White youth, being rearrested reduces legitimacy ratings from ages 16 through 23 .

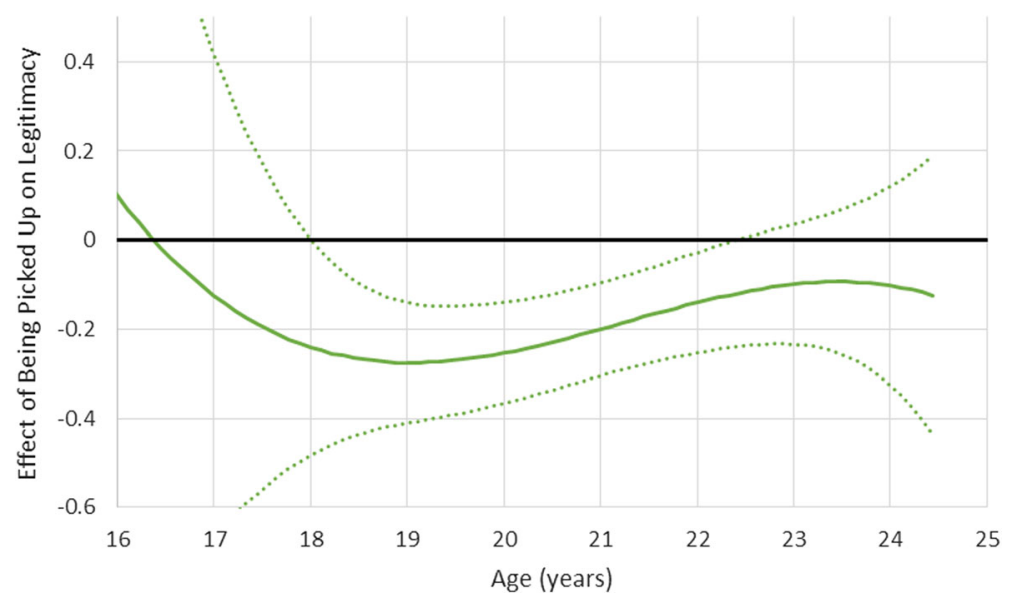

Fig. 6 Time-varying effects model of the effect of being picked up by the police on legitimacy scores for White youth. Note: Dotted lines indicate $95 \%$ confidence intervals. The $x$-axis indicates the effect of being picked up by the Police on youths' legitimacy ratings 


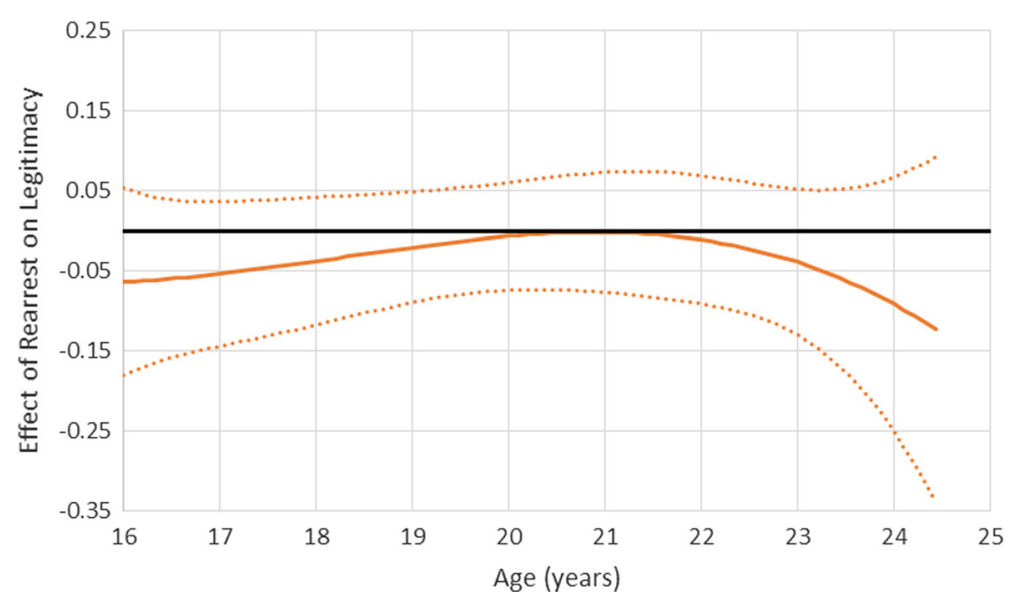

Fig. 7 Time-varying effects model of the effect of being rearrested on legitimacy scores for Latino youth. Note: Dotted lines indicate $95 \%$ confidence intervals. The $x$-axis indicates the effect of being rearrested on youths' legitimacy ratings

\section{Legal Cynicism}

Whereas perceptions of justice system legitimacy are related to greater confidence in the law, legal cynicism indicates whether an individual feels violating the law can be reasonable. To examine whether the developmental mechanisms underlying these attitudes vary, we repeat the same set of analyses using legal cynicism. To assess whether multilevel modeling was appropriate, unconditional means and growth models were run. The results of the unconditional means model suggest that $51.7 \%$ of the variability in legal cynicism occurred between participants. The results of the unconditional growth models suggest that there was variability in the intercept and slope of cynicism (Table 3$)$. Results of likelihood ratio $\chi^{2}$ tests for cynicism suggest that the random intercept is significant $\left(\chi^{2}=788.87, p<.001\right)$, random slope is significant

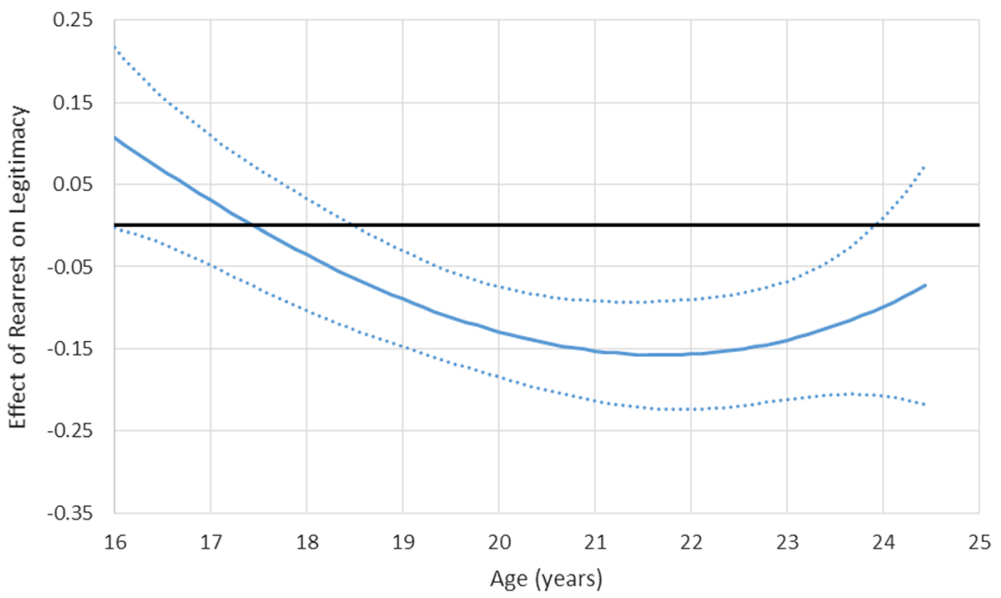

Fig. 8 Time-varying effects model of the effect of being rearrested on legitimacy scores for Black youth. Note: Dotted lines indicate $95 \%$ confidence intervals. The $x$-axis indicates the effect of being rearrested on youths' legitimacy ratings 


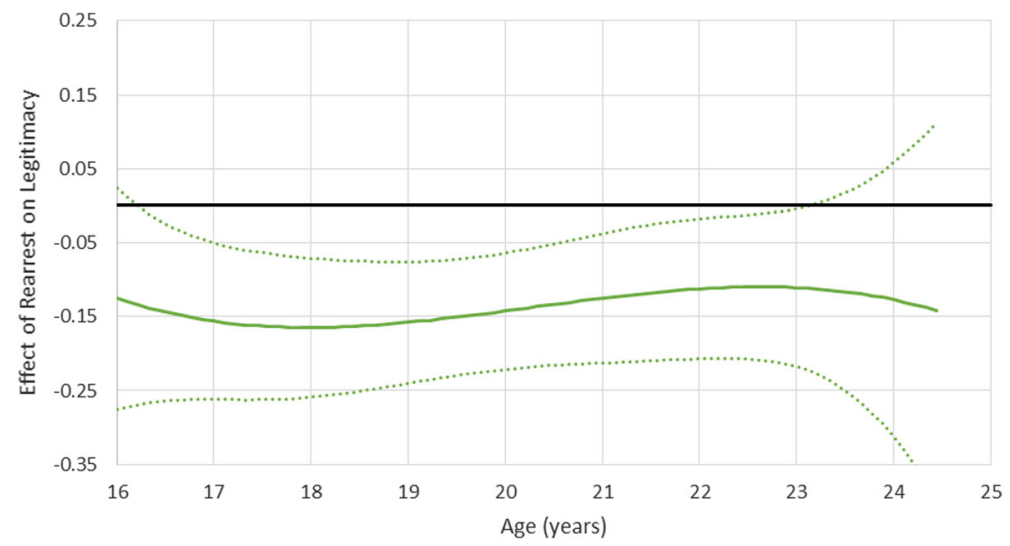

Fig. 9 Time-varying effects model of the effect of being rearrested on legitimacy scores for White youth. Note: Dotted lines indicate $95 \%$ confidence intervals. The $x$-axis indicates the effect of being rearrested on youths' legitimacy ratings

$\left(\chi^{2}=3210.87, p<.001\right)$, and covariance between intercepts and slopes is significant $\left(\chi^{2}=934.26, p<.001\right)$. These results indicate that multi-level modeling is appropriate.

Once it was established that multi-level modeling was appropriate, we added race/ethnicity to the model to examine whether race/ethnicity accounts for significant variability in cynicism (Fig. 10). It is important to note that these growth models appear different than the base means by age depicted in Table 1 because of the inclusion of the control variables. The likelihood ratio chi-square test between the model with and the model without race/ethnicity suggests that including race/ethnicity reduces error variability in cynicism $\left(\chi^{2}=32.33, p<.001\right)$. Results indicate that White youth report lower cynicism at age $14(M=1.94)$ than Black youth $(M=2.03, p=.059)$ and Latino youth $(M=2.12, p<.001)$, and these effects become more pronounced through age 25

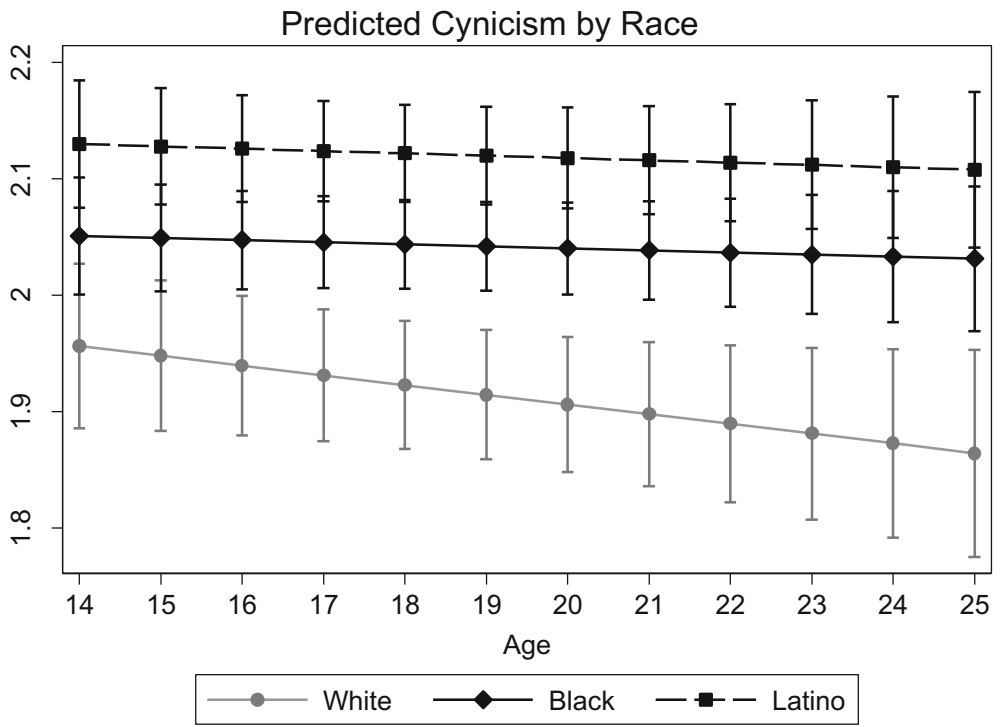

Fig. 10 Conditional growth model of cynicism using race 
$(p<.001)$. Black youth report lower cynicism than Latino youth at age $14(p=.011)$ through age $23(p=.048)$. At ages 24 and 25, there were no differences between Black and Latino youth $(p>.081)$. Including the interaction between race/ethnicity and age does not improve the model fit for cynicism $\left(\chi^{2}=1.36, p=.506\right)$. Results of a simple slopes analysis for cynicism that none of the slopes are significantly different from zero (White $(\mathrm{dy} / \mathrm{dx}=-.009, p=.083)$, Black $(\mathrm{dy} / \mathrm{dx}=-.002, p=.661)$, and Latino $(\mathrm{dy} / \mathrm{dx}=-.004$, $p=.315$ ) nor are any slopes significantly different from each other. These results indicate that cynicism remains relatively stable from adolescence through young adulthood. However, racial differences in cynicism appear in adolescence and remain through young adulthood.

Once it was established that the development of cynicism varies by race/ethnicity, we used time-varying effects modeling to examine the effects of personal contacts with the justice system on legal socialization. Figures 11, 12, and 13 present the results of the analyses examining the time-varying effects of being rearrested on cynicism ratings, separately by race/ethnicity. Results indicate that being picked up by the police only affects Latino youths' cynicism from ages 18 to 20. Being picked up by the police does not affect the cynicism ratings of Black or White youth. Figures 14, 15, and 16 present the results of the analyses examining the time-varying effects of being rearrested on cynicism ratings. Interestingly, being rearrested does not affect cynicism for any youth.

\section{Discussion}

Considering that justice system attitudes have direct consequences for crime commission during both adolescence and adulthood [1, 10, 24, 43, 60], it is essential to understand whether justice system attitudes remain stable from adolescence through early adulthood. Further, considering the salience of race/ethnicity to justice system exposure, it is likely that legal socialization experiences vary by race/ethnicity. However, race is one of the least explored constructs in life-course criminology [36]. Results of this study indicate that justice system attitude formation over the course of adolescence and early adulthood varies dramatically by race/ethnicity. For both

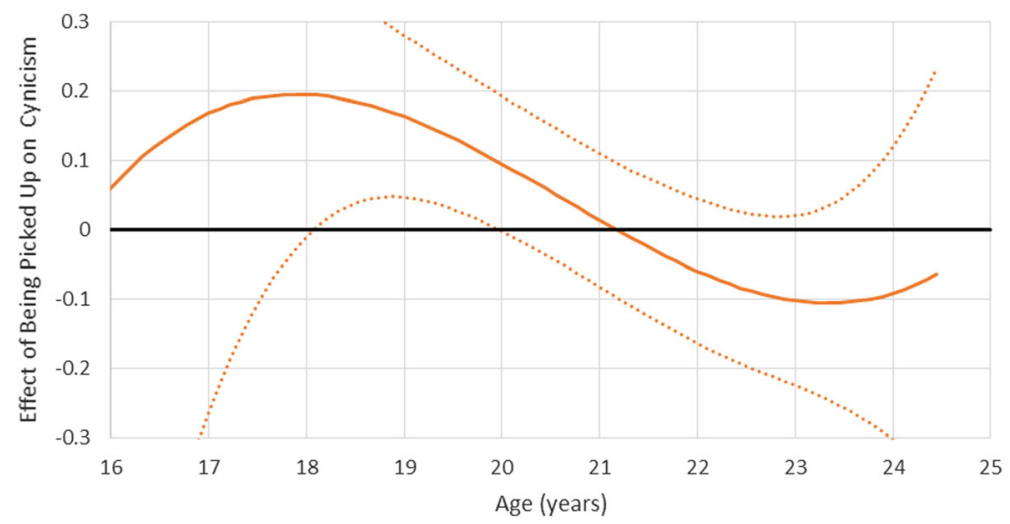

Fig. 11 Time-varying effects model of the effect of being picked up by the police on cynicism scores for Latino youth. Note: Dotted lines indicate $95 \%$ confidence intervals. The $x$-axis indicates the effect of being picked up by the Police on youths' cynicism ratings 


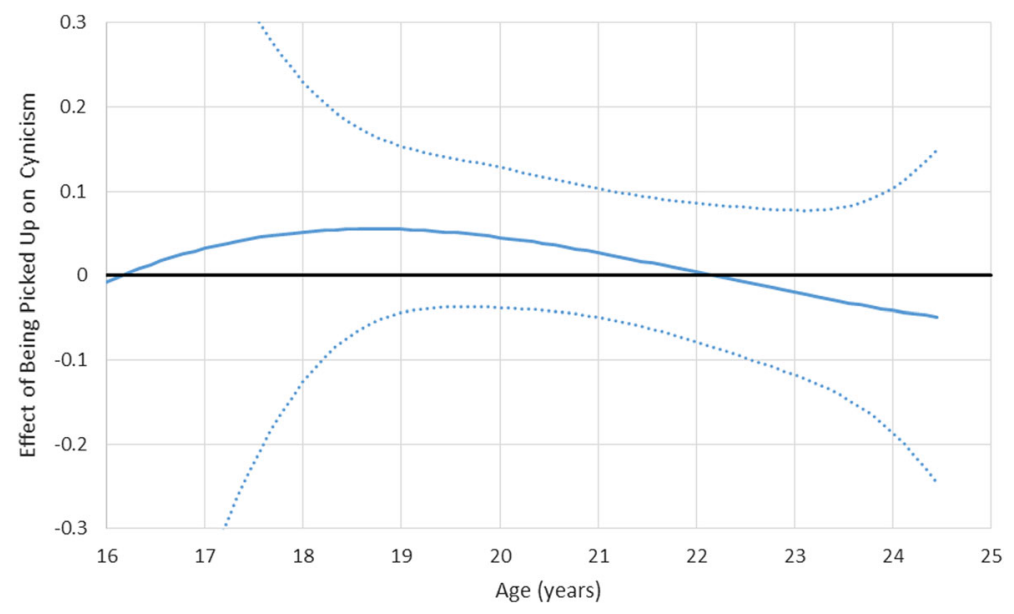

Fig. 12 Time-varying effects model of the effect of being picked up by the police on cynicism scores for Black youth. Note: Dotted lines indicate $95 \%$ confidence intervals. The $x$-axis indicates the effect of being picked up by the Police on youths' cynicism ratings

measures of justice system attitudes and for all ages assessed from adolescence through early adulthood, Black youth view the justice system the most negatively. Although surveys show that Latino adults report more negative attitudes than White adults (see [64]), the results of this study suggest that attitude differences emerge through adolescence. Latino and White youth report similar attitudes during adolescence, yet over time, White youth begin to view the system more positively than Latino youth. As indicated by the simple slopes analyses, Latino youths' attitudes do not significantly change over time. Results indicate that increasingly positive attitudes among White youth, and not increasingly negative attitudes among Latino youth, likely account for these differences. Indeed, White youth are the only group whose attitudes about the system become more positive as they age. Findings, in short, reveal a gradient in

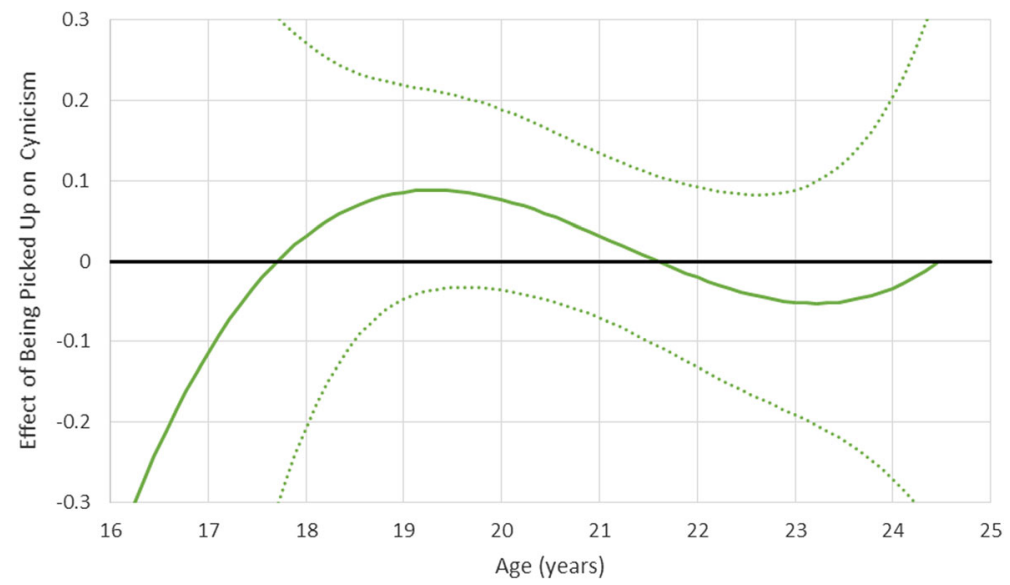

Fig. 13 Time-varying effects model of the effect of being picked up by the police on cynicism scores for White youth. Note: Dotted lines indicate $95 \%$ confidence intervals. The $x$-axis indicates the effect of being picked up by the Police on youths' cynicism ratings 


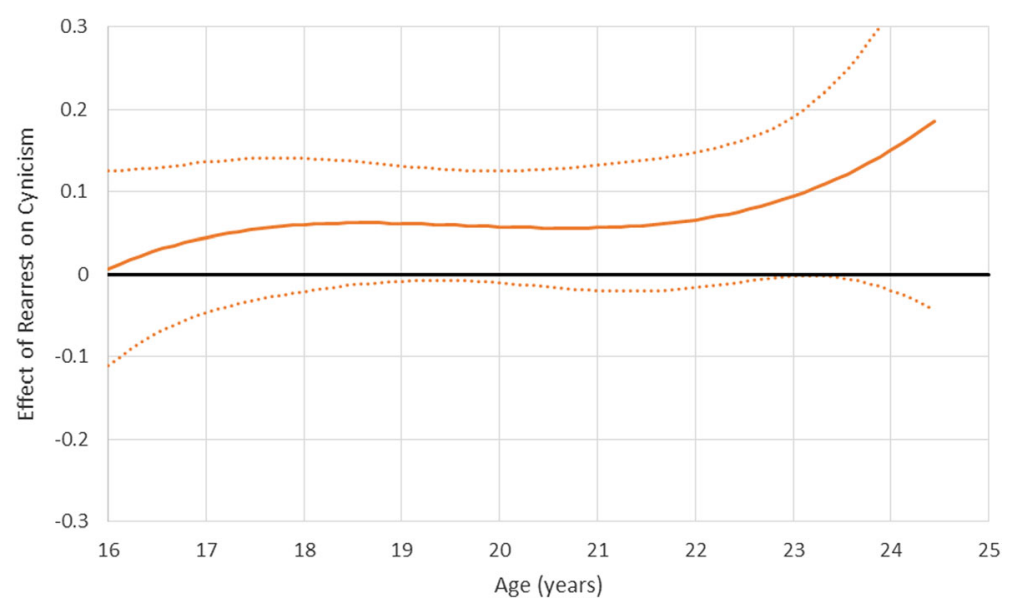

Fig. 14 Time-varying effects model of the effect of being rearrested on cynicism scores for Latino youth. Note: Dotted lines indicate $95 \%$ confidence intervals. The $x$-axis indicates the effect of being rearrested on youths' cynicism ratings

attitudes among White youth that begins in adolescence and becomes increasingly differentiated into early adulthood.

Considering the salience of race to justice system exposure, it is likely that justice system contacts also affect the legal socialization experiences differently by race. We find that the negative effects of personal experiences with the justice system on attitude development vary by age, race/ethnicity, the particular type of contact (i.e., being picked up by the police versus being rearrested), and the particular attitude. For Black youth, being picked up by the police affects legitimacy ratings at almost all ages, though actually being rearrested does not affect their perceptions of justice system legitimacy until early adulthood. Indeed, it may be the case that since Black youth were more likely to be picked up by the police and to be rearrested than either White or

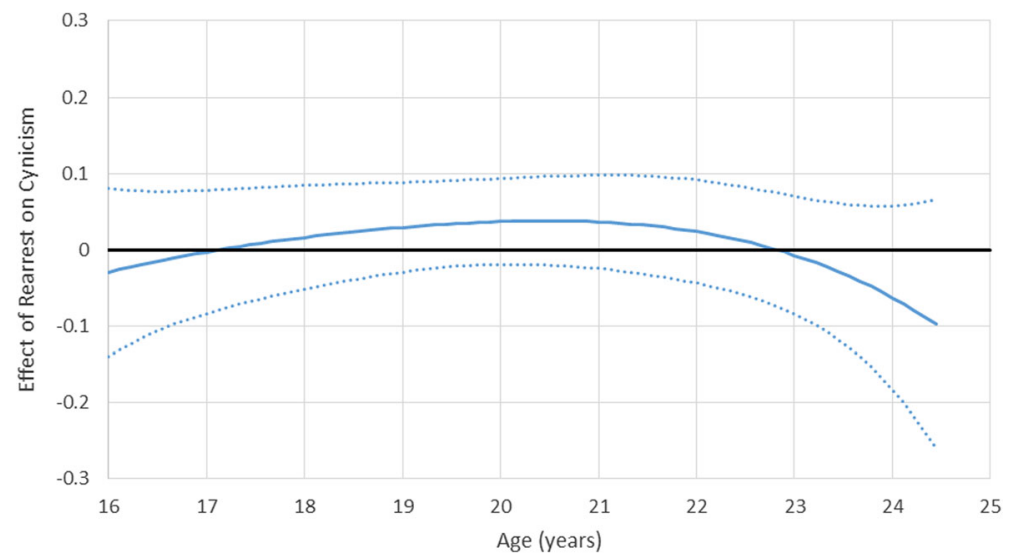

Fig. 15 Time-varying effects model of the effect of being rearrested on cynicism scores for Black youth. Note: Dotted lines indicate $95 \%$ confidence intervals. The $x$-axis indicates the effect of being rearrested on youths' cynicism ratings 


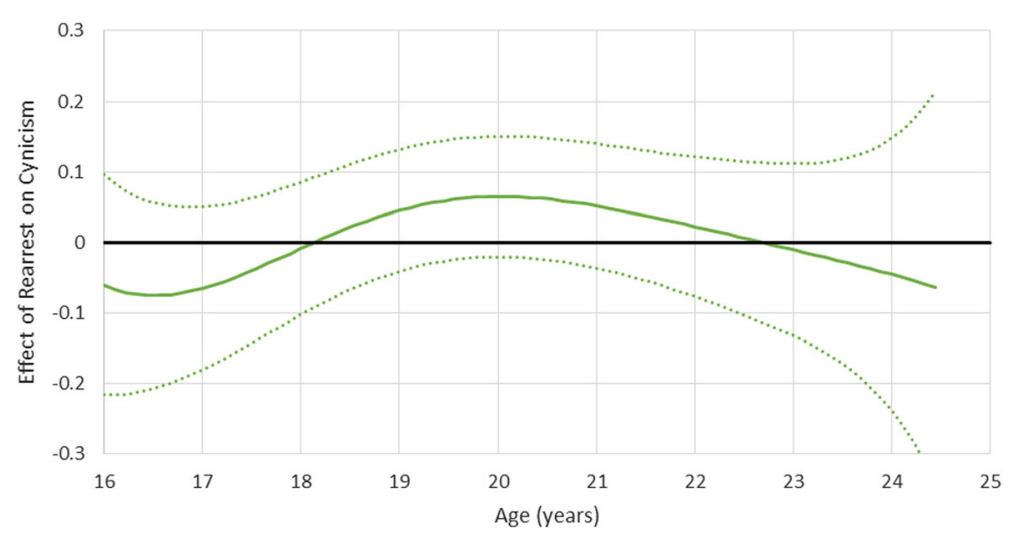

Fig. 16 Time-varying effects model of the effect of being rearrested on cynicism scores for White youth. Note: Dotted lines indicate $95 \%$ confidence intervals. The $x$-axis indicates the effect of being rearrested on youths' cynicism ratings

Latino youth over time, it is likely that these youths' disproportionate contact with the justice system may contribute to their more negative views of the justice system.

In contrast, neither being picked up by the police nor being rearrested significantly affects Latino youths' perceptions of justice system legitimacy. There are two possible explanations. First, although direct, personal experiences with the justice system affect attitudes towards the justice system, vicarious experiences, or what family members, neighbors, or friends communicate to the youth about their experiences with the justice system, also likely affect attitude development. It may be that vicarious experiences affect Latino youth's attitudes more than their direct, personal experiences. Second, in line with some prior research [60], it may be that Black youths in this study were treated more disrespectfully during police encounters than Latino or White youths. Accordingly, the effect of such encounters on attitude formation would be disproportionately larger for Black youth (see [29]). However, data on what occurred during these police encounters is unavailable; thus, additional research is necessary to examine these theoretical explanations. Considering this is the first developmental study spanning adolescence through early adulthood, future research with alternative datasets is necessary to understand why personal encounters with the justice system had limited effects on Latino youths' perceptions of the justice system.

Results also indicate that the effects of personal contacts with the justice system on attitude formation largely occur during young adulthood, as compared with adolescence. Young adulthood is a key transitional phase for young men, a time during which they generally move out of the home, seek self-sufficiency, employment, or higher education. The effects of justice system contacts may be disproportionately more negative during this transitional period when the young adult relies more on the self and less on the family. During adolescence, the family may be more involved in the youth's life, such that negative effects of justice system contacts may be more mitigated by familial involvement. Future research should examine whether relationships mitigate the effects of justice system experiences during different developmental periods.

This study has several limitations. First, because data were collected beginning at age 14 , it is unknown whether attitude development begins even before adolescence. Second, considering our statistical techniques require a large sample, this study focused 
exclusively on male offenders. Future research on the legal socialization of female offenders is necessary considering there may be baseline differences between the sexes that may contribute to differential legal socialization [11]. Third, this study only examined the effects of being picked up by the police or being rearrested on legal socialization. If minority youth describe the procedures used by legal authorities as more unfair, assessing what actually occurred during the contact may pronounce the effects found in this study. Complementing quantitative analyses with qualitative methods would enhance our understanding of the mechanisms in the legal socialization process, providing a more complete picture of not just the quantitative number of contacts, but a deeper understanding of what is happening during each of the contacts. This is particularly important considering minority youth tend to have disproportionate contact with justice system officials. Finally, this study did not examine the effects of vicarious justice system exposure on the development of attitudes towards the justice system. In accordance with the social developmental model [20], vicarious experiences with authorities likely shape youths' attitudes towards the justice system [9, 12, 22, 45]. Although emerging research suggests that vicarious negative experiences with justice system actors affect attitudes towards the justice system $[13,15]$, research has not examined whether these effects are limited to family members or friends, or if effects vary by developmental timing.

Despite these limitations, this study has several strengths, including the use of longitudinal statistical techniques. First, using longitudinal multilevel models enabled us to examine the trajectories of change in the legal socialization variables beginning in adolescence and continuing through early adulthood. Second, the use of the timevarying effects model enabled us to examine whether there was a time-varying relation between the covariates and the outcomes. Rather than estimating an overall effect of a time-varying covariate like rearrest, TVEM allows for the effect of each justice system contact on each legal socialization variable to be dynamic. These analytic tools give us greater confidence in our finding that not only does justice system attitude formation over the course of adolescence and early adulthood vary by race/ethnicity, but that the effects of personal experiences with justice system actors on attitude formation also varies by attitude, type of contact, age, and by race/ethnicity.

Although many of the study's hypotheses received support, we were surprised by our findings with legal cynicism. Despite a similar developmental trajectory for legal cynicism, we find that the mechanisms affecting legitimacy may not also affect legal cynicism. Results indicated that neither being picked up by the police nor being rearrested affected legal cynicism, with the exception of Latino youth briefly from ages 18 to 20. However, these results may be due to a threshold effect. That justice system contacts may affect legitimacy but not cynicism raises the importance of distinguishing between these attitudes. Cynicism refers to the degree to which individuals feel that the law does not apply to them and the degree to which an individual feels violating the law can be reasonable. In contrast, legitimacy refers to the individual's trust or confidence in the law. Repeated or negative interactions with justice system officials would likely erode one's trust in the legal system, one's legitimacy. These interactions, however, may not cause one to feel violating the law may be reasonable, nor may they actually cause one to break the law in the future. Understanding why youth feel violating the law is reasonable and what mechanisms worsen these attitudes would be particularly informative for practitioners. As such, additional research is necessary to identify what mechanisms affect the development of legal cynicism. 
This study was the first to examine how juvenile offenders' attitudes towards the justice system change during the transition to adulthood, and to demonstrate that the mechanisms of change vary based on developmental timing and race/ethnicity. The findings clearly indicate a gradient of justice system attitudes by race/ethnicity that begins in adolescence and becomes more pronounced into young adulthood. Black youth view the system as the least legitimate and most cynically, followed by Latino youth, and White youth. That mechanisms affect Black and Latino youth legal socialization differently indicates that aggregating minorities by analyzing all "non-Whites" together in future studies will mask meaningful differences. Considering that Black youth in this sample come into disproportionate contact with the justice system despite engaging in the same level of offending, it is likely that Black youth are recognizing a racial bias in the system. Their disproportionate contacts with the justice system likely erode their perceptions of its legitimacy. Though Black youths' attitudes towards the justice system are characterized as more negative, their attitudes may also be more realistic.

Acknowledgments The project described was supported by funds from the Office of Juvenile Justice and Delinquency Prevention, National Institute of Justice, John D. and Catherine T. MacArthur Foundation, William T. Grant Foundation, Robert Wood Johnson Foundation, William Penn Foundation, Centers for Disease Control, National Institute on Drug Abuse Grant R01DA019697, Pennsylvania Commission on Crime and Delinquency, and the Arizona Governor's Justice Commission. We are grateful for their support. The content of this paper, however, is solely the responsibility of the authors and does not necessarily represent the official views of these agencies.

\section{References}

1. Augustyn, M. (2015). The (ir)relevance of procedural justice in the pathways to crime. Law and Human Behavior, 39(4), 388-401.

2. Belli, R. (1998). The structure of autobiographical memory and event history calendar: potential improvements in the quality of retrospective reports in surveys. Memory, 6(4), 383-406. doi:10.1037/ lhb0000122.

3. Brandl, S., Frank, J., Worden, R., \& Bynum, T. (1994). Global and specific attitudes toward the police: disentangling the relationship. Justice Quarterly, 11(1), 119-134. doi:10.1080/07418829400092161.

4. Brick, B., Taylor, T., \& Esbensen, F. (2009). Juvenile attitudes towards the police: the importance of subcultural involvement and community ties. Journal of Criminal Justice, 37(5), 488-495. doi:10.1016/j. jcrimjus.2009.07.009.

5. Caspi, A., \& Amell, J. (1994). The reliability of life history calendar data. DPPP Tech. Report 94-01). Madison: University of Wisconsin.

6. Cohn, E., Bucolo, D., Rebellon, C., \& Van Gundy, K. (2010). An integrated model of legal and moral reasoning and rule-violating behavior: the role of legal attitudes. Law and Human Behavior, 34(4), 295309. doi:10.1007/s10979-009-9185-9.

7. Cohn, E., Trinkner, R., Rebellon, C., Van Gundy, K., \& Cole, L. (2012). Legal attitudes and legitimacy: extending the integrated legal socialization model. Victims \& Offenders, 7(4), 385-406. doi:10.1080/ 15564886.2012.713902.

8. Cohn, E., \& White, S. (1990). Legal socialization: a study of norms and rules. New York: Springer.

9. Collins, W. A., \& Laursen, B. (2004). Parent-adolescent relationships and influences. Handbook of Adolescent Psychology, 2, 331-362.

10. Fagan, J., \& Piquero, A. (2007). Rational choice and developmental influences on recidivism among adolescent felony offenders. Journal of Empirical Legal Studies, 4(4), 715. doi:10.1111/j.1740-1461. 2007.00105.x. 
11. Fagan, J., \& Tyler, T. (2005). Legal socialization of children and adolescents. Social Justice Research, 18(3), 217-241. doi:10.1007/s11211-005-6823-3.

12. Ferdik, F., Wolfe, S., \& Blasco, N. (2013). Informal social controls, procedural justice and perceived police legitimacy: do social bonds influence evaluations of police legitimacy? American Journal of Criminal Justice, 39(3), 471-492. doi:10.1007/s12103-013-9230-6.

13. Fine, A., Cavanagh, C., Donley, S., Steinberg, L., Frick, P., \& Cauffman, E. (in press). The role of peer arrests on the development of youths' attitudes towards the justice system. Law and Human Behavior.

14. Fitzmaurice, G., Laird, N., \& Ware, J. (2012). Applied longitudinal analysis. Wiley, 998.

15. Flexon, J. L., Lurigio, A. J., \& Greenleaf, R. G. (2009). Exploring the dimensions of trust in the police among Chicago juveniles. Journal of Criminal Justice, 37(2), 180-189. doi:10.1016/j.jcrimjus.2009.02. 006.

16. Freedman, D., Thornton, A., Camburn, D., Alwin, D., \& Young-Demarco, L. (1988). The life history calendar: a technique for collecting retrospective data. Sociological Methodology, 18, 37-68.

17. Geistman, J., \& Smith, B. W. (2007). Juvenile attitudes toward police: a national study. Journal of Crime and Justice, 30(2), 27-51. doi:10.1080/0735648X.2007.9721234.

18. Hagan, J., Shedd, C., \& Payne, M. R. (2005). Race, ethnicity, and youth perceptions of criminal injustice. American Sociological Review, 70(3), 381-407. doi:10.1177/000312240507000302.

19. Hastie, T., \& Tibshirani, R. (1993). Varying-coefficient models. Journal of the Royal Statistical Society: Series B: Methodological, 55(4), 757-796.

20. Hawkins, J. D., \& Weis, J. G. (1985). The social development model: an integrated approach to delinquency prevention. The Journal of Primary Prevention, 6(2), 73-97. doi:10.1007/BF01325432.

21. Huizinga, D., Esbensen, F.-A., \& Weiher, A. W. (1991). Are there multiple paths to delinquency? The Journal of Criminal Law and Criminology, 82(1), 83-118. doi:10.2307/1143790.

22. Hurst, Y., \& Frank, J. (2000). How kids view cops the nature of juvenile attitudes toward the police. Journal of Criminal Justice, 28, 189-202. doi:10.1016/S0047-2352(00)00035-0.

23. Hurst, Y., Frank, J., \& Lee Browning, S. (2000). The attitudes of juveniles toward the police: a comparison of black and white youth. Policing: An International Journal of Police Strategies \& Management, 23(1), 37-53.

24. Kirk, D., \& Matsuda, M. (2011). Legal cynicism, collective efficacy, and the ecology of arrest. Criminology, 49(2), 443-472. doi:10.1111/j.1745-9125.2011.00226.x.

25. Kirk, D., \& Papachristos, A. (2011). Cultural mechanisms and the persistence of neighborhood violence. American Journal of Sociology, 116(4), 1190-1233. doi:10.1086/655754.

26. Lee, J., Steinberg, L., Piquero, A., \& Knight, G. (2011). Identity-linked perceptions of the police among black juvenile offenders: a developmental perspective. Journal of Youth and Adolescence, 40(1), 23-37. doi:10.1007/s10964-010-9553-2.

27. Leiber, M., Nalla, M., \& Farnworth, M. (1998). Explaining juveniles' attitudes toward the police. Justice Quarterly, 15(1), 151-174. doi:10.1080/07418829800093671.

28. Li, R., Tan, X., Huang, L., Wagner, A. T., \& Yang, J. (2014). TVEM (time-varying effect model) SAS macro suite users' guide (Version 2.1.1). University Park: The Methodology Center, Penn State. Retrieved from: http://methodology.psu.edu.

29. Lurigio, A., Greenleaf, R., \& Flexon, R. (2009). The effects of race on relationships with the police: a survey of African American and Latino youths in Chicago. Western Criminology Review, 10, $29-41$.

30. Monahan, K., Steinberg, L., Cauffman, E., \& Mulvey, E. (2009). Trajectories of antisocial behavior and psychosocial maturity from adolescence to young adulthood. Developmental Psychology, 45(6), 1654 1668. doi:10.1037/a0015862.Trajectories.

31. Murphy, K. (2015). Does procedural justice matter to youth? Comparing adults' and youths' willingness to collaborate with police. Policing and Society, 25(1), 53-76. doi:10.1080/10439463.2013.802786.

32. Nivette, A., Eisner, M., Malti, T., \& Ribeaud, D. (2015). The social and developmental antecedents of legal cynicism. Journal of Research in Crime and Delinquency, 52(2), 270-298. doi:10.1177/ 0022427814557038.

33. Peck, J. (2015). Minority perceptions of the police: a state-of-the-art review. Policing: An International Journal of Police Strategies \& Management, 38(1), 173-203. doi:10.1108/PIJPSM-01-2015-0001.

34. Peffley, M., \& Hurwitz, J. (2010). Justice in America: the separate realities of blacks and whites. New York: Cambridge University Press.

35. Penner, E. K., Viljoen, J. L., Douglas, K. S., \& Roesch, R. (2014). Procedural justice versus risk factors for offending: predicting recidivism in youth. Law and Human Behavior, 38(3), 225-237. doi:10.1037/ lhb0000055. 
36. Piquero, A. (2015). Understanding race/ethnicity differences in offending across the life course: gaps and opportunities. Journal of Developmental Life-Course Criminology, 1, 21-32. doi:10.1007/s40865-0150004-3.

37. Piquero, A., Bersani, B., Loughran, T., \& Fagan, J. (2014). Longitudinal patterns of legal socialization in first-generation immigrants, second-generation immigrants, and native-born serious youthful offenders. Crime \& Delinquency, 1-23. doi:10.1177/0011128714545830

38. Piquero, A., Blumstein, A., Brame, R., Haapanen, R., Mulvey, E. P., \& Nagin, D. S. (2001). Assessing the impact of exposure time and incapacitation on longitudinal trajectories of criminal offending. Journal of Adolescent Research, 16(1), 54-74. doi:10.1177/0743558401161005.

39. Piquero, A., Fagan, J., Mulvey, E., Steinberg, L., \& Odgers, C. (2005). Developmental trajectories of legal socialization among serious adolescent offenders. Journal of Criminal Law and Criminology, 96(1), 1-29.

40. Puzzanchera, C. (2009). Juvenile arrests 2008. Washington, DC: U.S. Department of Justice, Office of Justice Programs, Office of Juvenile Justice and Delinquency Prevention.

NCJ Publication No 228479.

41. Puzzanchera, C., \& Hockenberry, S. (2013). Juvenile Court Statistics 2010.

42. Raudenbush, S. W., \& Bryk, A. S. (2002). Hierarchical linear models: applications and data analysis methods (2nd ed.). Thousand Oaks: Sage.

43. Reisig, M., Wolfe, S., \& Holtfreter, K. (2011). Legal cynicism, legitimacy, and criminal offending: the nonconfounding effect of low self-control. Criminal Justice and Behavior, 38(12), 1265-1279. doi:10. $1177 / 0093854811424707$.

44. Romain, D., \& Hassell, K. (2014). An exploratory examination of the sources of socialisation influencing juvenile perceptions of the police. International Journal of Police Science \& Management, 16(1), 36-51. doi:10.1350/ijps.2014.16.1.326.

45. Rosenbaum, D. (2005). Attitudes toward the police: the effects of direct and vicarious experience. Police Quarterly, 8(2001), 343-365. doi:10.1177/1098611104271085.

46. Sampson, R., \& Bartusch, D. (1998). Legal cynicism and (subcultural?) tolerance of deviance: the neighborhood context of racial differences. Law and Society Review, 32(4), 777-804.

47. Schubert, C., Mulvey, E., Steinberg, L., Cauffman, E., Losoya, S., Hecker, T., \& Knight, G. (2004). Operational lessons from the pathways to desistance project. Youth Violence and Juvenile Justice, 2(3), 119. doi: $10.1177 / 1541204004265875$.

48. Shiyko, M., Lanza, S., Tan, X., Li, R., \& Shiffman, S. (2012). Using the time-varying effect model (TVEM) to examine dynamic associations between negative affect and self confidence on smoking urges: differences between successful quitters and relapsers. Prevention Science, 13(3), 288-299. doi:10.1007/ s11121-011-0264-z.

49. Singer, J., \& Willett, J. (2004). Applied longitudinal data analysis (2004th ed.). New York: Oxford University Press.

50. Solis, C., Portillos, E., \& Brunson, R. (2009). Latino Youths' experiences with and perceptions of involuntary police encounters. The Annals of the American Academy of Political and Social Science, 623(1), 39-51. doi:10.1177/0002716208330487.

51. Srole, L. (1956). Social integration and certain corollaries: an exploratory study. American Sociological Review, 21(6), 709. doi:10.2307/2088422.

52. Stevens, T., \& Morash, M. (2014). Racial/ethnic disparities in boys' probability of arrest and court actions in 1980 and 2000: the disproportionate impact of "getting tough" on crime. Youth Violence and Juvenile Justice, 13, 77-95. doi:10.1177/1541204013515280.

53. Tan, X., Shiyko, M., Li, R., Li, Y., \& Dierker, L. (2012). A time-varying effect model for intensive longitudinal data. Psychological Methods, 17(1), 61-77. doi:10.1037/a0025814.

54. Tankebe, J. (2013). Viewing things differently: the dimensions of public perceptions of police legitimacy. Criminology, 51(1), 103-135. doi:10.1111/j.1745-9125.2012.00291.x.

55. TVEM SAS Macro Suite (Version 2.1.1) [Software]. (2014). University Park: The Methodology Center, Penn State. Retrieved from http://methodology.psu.edu.

56. Tyler, T. (1997). Procedural fairness and compliance with the law. Swiss Journal of Economics and Statistics, 133(2), 219-240.

57. Tyler, T. (2003). Procedural justice, legitimacy, and the effective rule of law. In M. Tonry (Ed.), Crime and justice: a review of research (Vol. 30, pp. 283-357). Chicago: University of Chicago Press.

58. Tyler, T. (2006). Psychological perspectives on legitimacy and legitimation. Annual Review of Psychology, 57, 375-400. doi:10.1146/annurev.psych.57.102904.190038.

59. Tyler, T. (2009). Legitimacy and criminal justice: the benefits of self-regulation. Ohio State Journal of Criminal Law, 7, 307-360. 
60. Tyler, T., \& Huo, Y. (2002). Trust in the law: encouraging public cooperation with the police and courts. New York: Russel Sage Foundation.

61. Tyler, T., \& Fagan, J. (2008). Legitimacy and cooperation: why do people help the police fight crime in their communities? Ohio State Journal of Criminal Law, 6, 231-275.

62. Vasilenko, S., \& Lanza, S. (2014). Predictors of multiple sexual partners from adolescence through young adulthood. Journal of Adolescent Health, 55(4), 491-497. doi:10.1016/j.jadohealth.2013.12.025.

63. Walls, T., \& Schafer, J. (Eds.). (2006). Modeling for intensive longitudinal data. New York: Oxford University Press.

64. Weitzer, R. (2014). The puzzling neglect of Hispanic Americans in research on police-citizen relations. Ethnic and Racial Studies, 37(11), 1995-2013. doi:10.1080/01419870.2013.790984.

65. Weitzer, R., \& Tuch, S. (2006). Race and policing in America: conflict and reform. New York: Cambridge University Press.

66. Woolard, J., Harvell, S., \& Graham, S. (2008). Anticipatory injustice among adolescents: age and racial/ ethnic differences in perceived unfairness of the justice system. Behavioral Sciences and the Law, 26, 207-226. doi:10.1002/bsl.

67. Yang, J., Tan, X., Li, R., \& Wagner, A. (2011). TVEM (Time-varying effect model) SAS Macro Suite User's Guide (Version 2.0). The Methodology Center, Penn State, 2012. 